\title{
HUBUNGAN PENERAPAN METODE COOPERATIVE LEARNING DENGAN HASIL BELAJAR SISWA
}

\author{
Nadiah \\ Universitas Islam Jakarta \\ email: nadiadiyaa@gmail.com
}

\begin{abstract}
Abstrak
Penelitian ini bertujuan untuk mendapatkan data yang tepat, sahih, valid serta dapat dipercaya dan diandalkan tentang Hubungan Penerapan Metode Cooperative Learning Dengan Hasil Belajar Siswa Teknik pengumpulan data menggunakan angket sebanyak 60 responden. Didukung pula dengan teknik observasi, wawancara dan studi dokumentasi. Sedangkan dalam menganalisis data menggunakan Product Moment dari Karl Pearson. Hasil penelitian dilihat dari segi uji koefisien Product Moment menghasilkan $r_{x y}$ atau $r_{o}$ sebesar $\mathbf{0 , 4 8 6}$ hal ini menunjukkan bahwa $r_{o}$ lebih besar dari pada $r_{t}$ pada taraf signifikan $5 \%=\mathbf{0 , 2 5 4}$ dan taraf signifikan $1 \%=\mathbf{0 , 4 1 3}$. Membandingkan besarnya " $\mathrm{r}_{\mathrm{xy}}$ " dengan " $\mathrm{r}_{\mathrm{t}}$ " seperti yang diketahui $\mathrm{r}_{\mathrm{xy}}$ yang peneliti peroleh adalah $=\mathbf{0 , 4 8 6}$, sedangkan $r_{t}$ masing-masing 0,354 dan $\mathbf{0 , 4 1 3}$. Dengan demikian ternyata bahwa $r_{x y}>r_{t}$ baik pada taraf signifikan $5 \%$ atau $1 \%$, Dalam hal ini berarti bahwa terdapat hubungan yang sedang atau cukup antara penerapan metode cooperative learning dengan hasil belajar siswa. Korelasi tersebut adalah penerapan metode cooperative learning sebagai metode yang efektif terhadap hasil belajar siswa. Dari hasil penelitian ini, maka dapat disimpulkan bahwa Penerapan Metode Cooperative Learning memiliki hubungan yang sedang atau cukup dengan hasil belajar siswa.
\end{abstract}

Kata- kata kunci : Metode, Cooperative Learning, Hasil Belajar

\section{APPLICATION OF COOPERATIVE LEARNING METHOD WITH STUDENT LEARNING OUTCOMES}

\author{
Nadiah \\ Universitas Islam Jakarta \\ email: nadiadiyaa@gmail.com
}

\begin{abstract}
This study aims to obtain the right data, valid, valid and reliable and reliable about the Relationship Application of Cooperative Learning Method With Student Results Data collection techniques using questionnaires as many as 60 respondents. Also supported by observation techniques, interviews and documentation studies. While in analyzing data using Product Moment from Karl Pearson. The result of the research is seen from the terms of Product Moment coefficient test yielding rxy or ro equal to 0.486 it shows that ro is bigger than $\mathrm{rt}$ at significant level $5 \%=0,254$ and significant level $1 \%=0,413$. Comparing the amount of "rxy" with "rt" as known rxy that researchers obtain is $=0.486$, while rt respectively 0.354 and 0.413 . Thus it turns out that rxy> rt either at a significant level of $5 \%$ or $1 \%$, In this case means that there is a moderate or sufficient relationship between the application of cooperative learning method with student learning outcomes. Correlation is the application of cooperative learning method as an effective method of student learning outcomes. From the results of this study, it can be concluded that the implementation of Cooperative Learning method has a moderate or sufficient relationship with student learning outcomes.
\end{abstract}

Keywords: Method, Cooperative Learning, Learning Outcomes 


\section{PENDAHULUAN}

Belajar merupakan suatu kegiatan yang dilakukan secara teratur serta terencana guna mencapai tujuan. Dengan adanya kegiatan belajar teratur, maka hasil belajar juga akan meningkat. Oleh karena itu untuk mencapai hasil belajar terlebih dahulu melalui proses belajar. Belajar sebagai suatu kegiatan tentunya mempunyai pengaruh dalam keberhasilan belajar. Terdapat dua faktor yang mempengaruhi hasil belajar siswa yaitu faktor internal dan eksternal. Faktor internal yaitu faktor yang ada pada diri siswa itu sendiri yang terdiri atas faktor jasmaniah, psikologi, minat, motivasi dan cara belajar., sedangkan faktor eksternal yaitu faktor keluarga, sekolah dan masyarakat.

Salah satu faktor eksternal yang mempengaruhi hasil belajar siswa adalah faktor sekolah, yang mencakup metode mengajar, kurikulum, relasi guru siswa, sarana dan prasarana.Penggunaan metode pembelajaran menjadi salah satu hal yang dapat menunjang proses kegiatan belajar mengajar di kelas menjadi kondusif. Dengan berbagai metode pengajaran pula diharapkan media pembelajaran tersebut lebih efektif digunakan dan proses belajar mengajar pun menjadi lebih menarik bagi peserta didik.

Penggunaan metode belajar yang biasanya digunakan oleh guru dalam pembelajaran Agama Islam di sekolah adalah pembelajaran yang terpusat pada guru. Guru dianggap sebagai sumber utama dari ilmu. Sehingga kebanyakan siswa menjadi kurang berkembang dan tidak mengeksplorasi kemampuan dirinya. Untuk itu perlu mengubah paradigma pembelajaran dari teacher centered ke paradigma student centered. Dengan demikian guru diharapkan mampu menguasai serta mengaplikasikan berbagai macam strategi pengajaran yang berpusat pada siswa. Proses pengajaran di sekolah tidak terlepas dari konsep yang akan diajarkan. Namun, pada penyampaian materi di kelas, guru lebih sering menggunakan metode ceramah yang hanya menggunakan media papan tulis dan spidol saja yang dianggap relatif mudah dan murah, padahal hal ini membuat siswa menjadi kurang tertarik, bosan, mengobrol dan bahkan tidak jarang dari mereka tidak mau belajar. Ini menjadi masalah yang harus dihadapi oleh setiap guru. Seringnya murid mengobrol ketika guru menjelaskan membuat proses pembelajaran menjadi tidak kondusif. Namun demikian bukan berarti itu merupakan kesalahan total dari seorang siswa. Kemungkinan ada dua permasalahan, yakni dari pihak siswa itu sendiri yang malas atau dari pihak guru yang terlalu monoton dalam mengajarnya.

Dalam mengasah pemahaman siswa guru pun seharusnya mengajak siswa untuk berpartisipasi langsung dalam kegiatan pembelajaran. Dari berbagai kekurangan itu, 
tidak menjadikan guru Agama Islam menjadi tidak kreatif. Terdapat banyak metode pembelajaran yang dapat dijadikan solusi untuk menggantikan metode ceramah yang biasa guru terapkan.

Berdasarkan berbagai permasalahan di atas, maka terdapat solusi yang dapat digunakan yaitu sebuah metode yang dapat membuat siswa aktif berperan dalam pembelajaran yakni metode diskusi. Metode ini dapat dijadikan solusi untuk menyelesaikan masalah-masalah siswa seperti siswa yang tidak memperhatikan, siswa yang bosan, atau siswa yang tidak mau belajar. Penerapan metode diskusi akan membuat siswa mau tidak mau harus ikut berperan dalam pembelajaran, dalam hal ini disebut dengan metode pembelajaran kooperatif.

\section{METODE PENELITIAN}

Pendekatan penelitian menggunakan pendekatan kuantitatif sedangkan metode penelitian yang digunakan adalah menggunakan metode studi korelasi yang merupakan bagian dari jenis penelitian deskriptif kuantitatif.

Deskriptif adalah penelitian yang bertujuan memberikan gambaran secara umum, sistematis, faktual, akurat mengenai fakta-fakta, sifat-sifat serta hubungan antara fenomena yang diselidiki. Sedangkan kuantitatif adalah penelitian yang disajikan dalm bentuk deskriptif dengan menggunakan angka-angka statistik.

Teknik pengumpulan data yang digunakan dalam penelitian ini meliputi penelitian kepustakaan dan penelitian lapangan. Penelitian kepustakaan ( Library Research ) yaitu suatu suatu penyelidikan yang diadakan dalam rangka memproleh fakta-fakta dan data-data melalui kajian pustaka dan dokumen yang relevan dengan masalah yang sedang diteliti. Sementara penelitian lapangan ( Field Research) yaitu suatu penyelidikan yang diadakan untuk memperoleh fakta-fakta dan gejala-gejala yang ada dan mencari keterangan-keterangan secara faktual. Data itu diperoleh melalui observasi. Sebagai metode ilmiah observasi biasa diartikan sebagai pengamat dan pencatatan dengan statistik fenomena yang di selidiki. Dalam hal ini penulis melakukan pengamatan langsung di SMKN 5 Jakarta Timur. Observasi ini digunakan untuk mendapatkan data yang lebih objektif jika di lakukan pengamatan secara langsung. Mengamati data secara langsung akan memudahkan dalam menganalisa data-data tersebut. Kedua, data penelitian ini diperoleh dari angket. Metode ini ditunjukan kepada siswa yang dijadikan responden untuk mendapatkan data dan informasi yang berhubungan dengan penerapan metode cooperative learning dengan hasil belajar di SMKN 5 Jakarta Timur yang berjumlah 60 orang siswa. Kuesioner yang dibuat 
merupakan kuesioner tertutup, dan terdiri dari 25 item pernyataan dengan menggunakan skala Likert.

Ketiga, studi dokumentasi. Studi dokumentasi ini dilakukan untuk mengetahui hasil belajar siswa dengan melihat nilai ujian semester siswa kelas XI semester ganjil di SMKN 5 Jakarta Timur.

Keempat, wawancara. Wawancara adalah suatu teknik pengumpulan data dengan cara mengadakan komunikasi dengan sumber data. Komunikasi tersebut dilakukan dengan dialog (tanya jawab) secara lisan, baik langsung maupun tidak langsung. (Sugiyono,2009;96).

Untuk menganalisa data, peneliti menggunakan analisa deskriptif yang bertujuan untuk membuat deskriptif atau gambaran secara sistematis faktual dan akurat mengenai fakta-fakta dan sifat-sifat yang teliti. Teknik perhitungan dari angket akan dianalisis menggunakan teknik persentase untuk memperoleh korelasi dengan rumus :

$$
r_{y y}=\frac{N \sum x y-\left(\sum x\right)\left(\sum y\right)}{\sqrt{N \sum x^{2}-\left(\sum x\right)^{2} N \sum y^{2}-\left(\sum y\right)^{2}}}
$$

Keterangan :

$r_{x y} \quad:$ Angket indeks korelasi antara variabel $\mathrm{x}$ dan variabel $\mathrm{y}$

$N$ : Jumlah responden

$\sum x y$ : Jumlah hasil perkalian $\mathrm{x}$ dan $\mathrm{y}$

$y \quad$ : Jumlah skor $\mathrm{y}$

$x \quad$ : Jumlah skor $\mathrm{x}$ $x^{2}$ : Jumlah kuadrat seluruh skor 2

$y^{2}$ : Jumlah kuadrat seluruh skor 2

\section{HASIL DAN PEMBAHASAN}

Berdasarkan perhitungan, diperoleh korelasi antara hasil penelitian kuesioner Hubungan Penerapan Metode Cooperative Learning Dengan Hasil Belajar Siswa, maka dapat dilihat pada perhitungan di bawah ini, pada koefisien korelasi $\mathbf{0 , 4 8 6}$ atau 48,6 \%. Untuk mengetahui hubungan antara dua variabel yang sedang diteliti terdapat cara menginterpretasikannya,Dan memberikan interpretasi terhadap Angka Indeks Korelasi Product Moment secara sederhana.

$$
\begin{aligned}
& r_{x y}=\frac{N \sum x y-\left(\sum x\right)\left(\sum y\right)}{\sqrt{\left\{N \sum x^{2}-\left(\sum x\right)^{2}\right\}\left\{N \sum y^{2}-\left(\sum y\right)^{2}\right\}}} \\
& r_{x y}=\frac{60.414018-(5261)(4704)}{\sqrt{\left\{60.463905-(5261)^{2}\right\}\left\{60.372736-(4704)^{2}\right\}}} \\
& r_{x y}=\frac{24841080-24747744}{\sqrt{\{27834300-27678121\}\{22364160-22127616}}
\end{aligned}
$$

$$
r_{x y}=\frac{93336}{\sqrt{(156179)(236544)}}
$$

$$
r_{x y}=\frac{93336}{\sqrt{36943205376}}
$$

$r_{x y}=\frac{93336}{192206,153}$

$$
r_{x y}=0,486
$$


Dari perhitungan di atas, telah berhasil diperoleh $r_{x y}$ sebesar $\mathbf{0 , 4 8 6}$. Jika diperhatikan, maka angka indeks korelasi yang telah penulis peroleh itu bertanda positif. Ini berarti korelasi antara veriabel $\mathrm{X}$ (Penerapan Metode Cooperative Learning) dan variabel Y (Hasil Belajar Siswa) ada hubungan yang searah pada penelitian ini. Artinya Penerapan Metode Cooperative Learning berhubungan dengan Hasil Belajar Siswa. Apabila dilihat $r_{x y}$ yang diperoleh yaitu $\mathbf{0 , 4 8 6}$ ternyata terletak antara $\mathbf{0 , 4 0}-\mathbf{0 , 7 0}$.

\section{Angka Indeks Korelasi Product Moment}

\begin{tabular}{|l|l|}
\hline $\begin{array}{l}\text { Besarnya "r" } \\
\text { Product } \\
\text { Moment }\left(\mathrm{r}_{\mathrm{xy}}\right)\end{array}$ & \multicolumn{2}{|c|}{ Interprestasi } \\
\hline $0,00-0,20$ & $\begin{array}{l}\text { Antara variabel X dan variabel Y } \\
\text { terdapat korelasi, akan tetapi } \\
\text { korelasi ini sangat lemah atau } \\
\text { sangat rendah, sehingga korelasi itu } \\
\text { diabaikan (dianggap tidak ada } \\
\text { korelasi antara variabel X dan } \\
\text { Variabel Y) }\end{array}$ \\
\hline $0,20-0,40$ & $\begin{array}{l}\text { Antara variabel X dan variabel Y } \\
\text { terdapat korelasi yang lemah atau } \\
\text { rendah }\end{array}$ \\
\hline $\mathbf{0 , 4 0 - 0 , 7 0}$ & $\begin{array}{l}\text { Antara variabel X dan variabel Y } \\
\text { terdapat korelasi yang sedang } \\
\text { atau cukup }\end{array}$ \\
\hline $0,70-0,90$ & $\begin{array}{l}\text { Antara variabel X dan variabel Y } \\
\text { terdapat korelasi yang kuat atau } \\
\text { tinggi }\end{array}$ \\
\hline $0,90-1,00$ & $\begin{array}{l}\text { Antara variabel X dan variabel Y } \\
\text { terdapat korelasi yang sangat kuat } \\
\text { atau sangat tinggi }\end{array}$ \\
\hline
\end{tabular}

(Sumber: JP Guilford dalam Fundamental Statistic in psychology and education dalam Sudjono 2011:180).
Berdasarkan pedoman yang terdapat pada tabel dapat dinyatakan bahwa antara korelasi variabel $\mathrm{X}$ dan variabel $\mathrm{Y}$ adalah korelasi yang tergolong sedang atau cukup.

Berdasarkan data yang telah dikumpulkan dan dianalisis secara teliti dan cermat. Kemudian melakukan pembahasan lebih lanjut terhadap analisis data. Dilakukan pembahasan mengenai pendapat peneliti setelah dibandingkan teori dengan penerapan dari teori tersebut dalam uraian.

Berdasarkan hasil pengujian yang telah dilakukan di lapangan, maka terbukti bahwa Penerapan Metode Cooperative Learning berhubungan dengan hasil belajar siswa.

Hal ini juga diperkuat oleh pendapat guru Pendidikan Agama Islam (PAI), bahwa dengan menerapkan metode cooperative dalam belajar maka siswa akan lebih terdorong untuk aktif diskusi di kelas sehingga kemampuan yang ada pada diri siswa terlihat saat diskusi atau kerja kelompok berlangsung sehingga hal ini juga dapat mempengaruhi hasil belajar siswa (Ja'far, Selasa, 15 -08-2017).

Wakil kepala sekolah SMKN 5 juga mengatakan, bahwa semakin baik dan tepat metode belajar yang diterapkan guru di dalam kelas maka akan berpengaruh terhadap hasil belajar siswa (Adip, Rabu, 16-08-2017). 
Dari hasil penelitian didapatkan bahwa hasil korelasi yang diperoleh dapat dikatakan sebagai korelasi yang sedang atau cukup, yang hasilnya sebesar $\mathbf{0 , 4 8 6}$. Berarti terdapat hubungan penerapan metode cooperative learning dengan hasil belajar siswa.

Dari hasil tersebut diketahui bahwa penerapan metode cooperative learning berhubungan dengan hasil belajar siswa dengan tingkat korelasinya sedang atau cukup yaitu antara $\mathbf{0 , 4 0}-\mathbf{0 , 7 0}$, jadi dapat dimengerti bahwa metode cooperative learning berhubungan dengan hasil belajar siswa sebesar 23,6 \% dan sisanya sebesar $\mathbf{7 6 , 4} \%$ dipengaruhi oleh faktor lain, seperti kesehatan, cacat tubuh, inteligensi, bakat, minat, motif, kesiapan, cara orangtua mendidik, relasi antaranggota keluarga, keadaan ekonomi keluarga, suasana rumah, kurikulum, alat pelajaran, kegiatan siswa di masyarakat, mass media, teman bergaul, dan bentuk kehidupan masyarakat.

Penerapan metode cooperative learning adalah salah satu cara yang efektif untuk mendapat hasil belajar siswa yang baik. Semakin banyak guru yang bisa menerapkan metode cooperative learning dengan baik di dalam kelas, maka hasil belajar siswa diharapkan akan menjadi lebih baik. Kepala sekolah harus memperhatikan tenaga pengajar dalam menggunakan metode belajar di kelas agar anak didik mendapat hasil belajar yang baik.

\section{KESIMPULAN DAN SARAN}

Hubungan yang signifikan antara penerapan metode cooperative learning dengan hasil belajar siswa kelas XI tahun pelajaran 2012-2013 di SMKN 5 Jakarta Timur. Terdapat hubungan penerapan metode cooperative learning dengan hasil belajar siswa sebesar $\mathbf{0 , 4 8 6}$. Hal ini dapat dilihat dari besarnya " $r_{0}$ " dengan " $r_{t}$ " seperti yang diketahui $r_{o}$ yang peneliti peroleh adalah $\mathbf{0 , 4 8 6}$, sedangkan $r_{t}$ masing-masing 0,254 dan 0,413. Dengan demikian ternyata bahwa $r_{o}>r_{t}$ baik pada taraf signifikan $5 \%$ atau $1 \%$. Maka hipotesis nihil ditolak, sedangkan hipotesis alternatif diterima atau disetujui, artinya terdapat hubungan antara penerapan metode cooperative learning dengan hasil belajar siswa di SMKN 5 Jakarta Timur.

Besarnya hubungan antara penerapan metode cooperative learning model group investigation dengan hasil belajar siswa termasuk sedang atau cukup yaitu antara $\mathbf{0 , 4 0}-\mathbf{0 , 7 0}$. Hal ini menunjukkan adanya hubungan adanya penerapan metode cooperative learning yang selalu memberikan motivasi atau dorongan kepada siswa untuk aktif dalam kegiatan pembelajaran mulai dari perencanaan hingga akhir kegiatan pembelajaran. Oleh karena itu pendidik harus bisa menggunakan metode yang tepat dan sesuai dengan kebutuhan siswa agar 
tidak ada lagi siswa yang merasa bosan atau jenuh untuk mengikuti pelajaran bahkan tidak mau belajar. Pendidik juga harus bisa menggunakan metode belajar yang dapat membuat siswa berperan aktif dalam pembelajaran sehingga dengan begitu hasil belajar siswa akan baik. Dan selain pendidik lembaga pendidikan agar dapat mengetahui pentingnya penggunaan metode cooperative learning dalam proses belajar mengajar di sekolah.

\section{DAFTAR PUSTAKA}

Ames, C \& Archer, J. 1988 Achievment goals in the classroom : students' learning strategies and motivation processes. Journal of Education, 3, 260-270.

Atkinson. R. K. , 2002 Optimizing Learning From Examples Using Pedagogical Agents. Journal of Education , 94 (2), 416427.

Isjoni, 2011. Pembelajaran Kooperatif, Yogyakarta: Putaka Pelajar.
Muslimin Ibrahim, dkk. 2001. Pembelajaran Kooperatif, Surabaya: Uniersity Press.

Molyneux, L. 1992. Cooperative Learning, Science and Success: step-by-step Activities. New York: Trellis Book

Sharan, Shlomo, 2012. Handbook Of Cooperative Learning, Yogyakarta: Familia.

Sydarwan Danim, 2010, Pedagogi,Andragogi dan heutagogi, Alfabeta, Bandung.

Suprijono, Agus. 2011. Cooperative Learning, Yogyakarta: Pustaka Belajar.

Sudjono Fundamental Statistic in psychology and education 2011:180.

Slameto. 2010. Belajar dan Faktor-faktor yang mempengaruhinya, Jakarta: Rineka Cipta.

Uyoh Sadulloh, 2010, Pedgogik (Ilmu Mendidik), Alfabeta, Bandung.

Wina Sanjaya, 2009. Perencanaan dan Desain Sistem Pembelajaran, Jakarta: kencana prenada media group.

Wena Made, 2011. Strategi Pembelajaran Inovatif Kontemporer, Jakarta: Bumi Aksara 